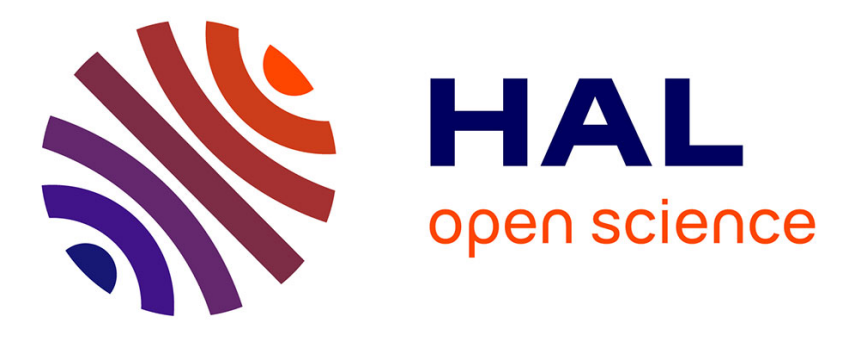

\title{
Effect of pressure on Hydrogen/Oxygen coupled flame-wall interaction
}

Raphaël Mari, Bénédicte Cuenot, Jean-Philippe Rocchi, Laurent Selle, Florent Duchaine

\section{- To cite this version:}

Raphaël Mari, Bénédicte Cuenot, Jean-Philippe Rocchi, Laurent Selle, Florent Duchaine. Effect of pressure on Hydrogen/Oxygen coupled flame-wall interaction. Combustion and Flame, 2016, 168, pp.409-419. 10.1016/j.combustflame.2016.01.004 . hal-01320335

\section{HAL Id: hal-01320335 https://hal.science/hal-01320335}

Submitted on 23 May 2016

HAL is a multi-disciplinary open access archive for the deposit and dissemination of scientific research documents, whether they are published or not. The documents may come from teaching and research institutions in France or abroad, or from public or private research centers.
L'archive ouverte pluridisciplinaire HAL, est destinée au dépôt et à la diffusion de documents scientifiques de niveau recherche, publiés ou non, émanant des établissements d'enseignement et de recherche français ou étrangers, des laboratoires publics ou privés. 


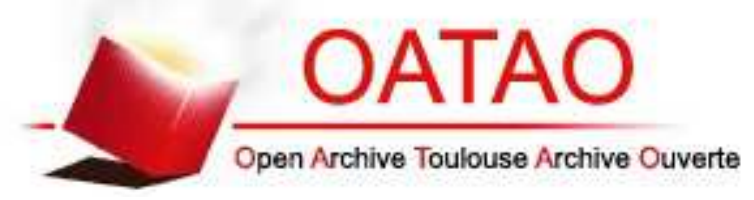

\section{Open Archive TOULOUSE Archive Ouverte (OATAO)}

OATAO is an open access repository that collects the work of Toulouse researchers and makes it freely available over the web where possible.

This is an author-deposited version published in : http://oatao.univ-toulouse.fr/ Eprints ID : 15676

To link to this article : DOI:10.1016/j.combustflame.2016.01.004 URL : http://dx.doi.org/10.1016/j.combustflame.2016.01.004

\section{To cite this version :}

Mari, Raphaël and Cuenot, Bénédicte and Rocchi, Jean-Philippe and Selle, Laurent and Duchaine, Florent Effect of pressure on

Hydrogen/Oxygen coupled flame-wall interaction. (2016)

Combustion and Flame, vol. 168. pp. 409-419. ISSN 0010-2180

Any correspondence concerning this service should be sent to the repository administrator: staff-oatao@ listes-diff.inp-toulouse.fr 


\title{
Effect of pressure on hydrogen/oxygen coupled flame-wall interaction
}

\author{
Raphael Mari ${ }^{\mathrm{a}, *}$, Benedicte Cuenot ${ }^{\mathrm{a}}$, Jean-Philippe Rocchi ${ }^{\mathrm{a}}$, Laurent Selle ${ }^{\mathrm{b}}$, \\ Florent Duchaine ${ }^{\mathrm{a}}$
}

${ }^{a}$ CERFACS, 42 av G. Coriolis, 31057 Toulouse, France

${ }^{\mathrm{b}}$ CNRS, IMFT, F-31400 Toulouse, France

Keywords:

Real-gas thermodynamics

Flame-wall interaction

Conjugate heat transfer

\begin{abstract}
A B S T R A C T
The design and optimization of liquid-fuel rocket engines is a major scientific and technological challenge. One particularly critical issue is the heating of solid parts that are subjected to extremely high heat fluxes when exposed to the flame. This in turn changes the injector lip temperature, leading to possibly different flame behaviors and a fully coupled system. As the chamber pressure is usually much larger than the critical pressure of the mixture, supercritical flow behaviors add even more complexity to the thermal problem. When simulating such phenomena, these thermodynamic conditions raise both modeling and numerical specific issues. In this paper, both subcritical and supercritical hydrogen/oxygen one-dimensional, laminar flames interacting with solid walls are studied by use of conjugate heat transfer simulations, allowing to evaluate the wall heat flux and temperature, their impact on the flame as well as their sensitivity to high pressure and real gas thermodynamics up to 100 bar where real gas effects are important. At low pressure, results are found in good agreement with previous studies in terms of wall heat flux and quenching distance, and the wall stays close to isothermal. On the contrary, due to important changes of the fluid transport properties and the flame characteristics, the wall experiences significant heating at high pressure condition and the flame behavior is modified.
\end{abstract}

\section{Introduction}

Most of high performance propulsion devices such as turbines, rocket engines or scramjets operate in wall-bounded flows. The interaction between flame and walls has a direct and strong impact on combustion, pollutant emissions and combustion chamber lifetime. Understanding the mechanisms at play in flame-wall interaction (FWI) is therefore necessary to further gain in performance, safety, fuel consumption and unburnt gas emission. As shown in [1,2], local FWI may be described in simple laminar flows where generic flame configurations may be introduced. During the flame-wall interaction process, the flame speed and thickness decrease, before full quenching at a few microns away from the wall. When the flame approaches the wall, the temperature decreases from burnt gases (approximately $3000 \mathrm{~K}$ for hydrogen $\left(\mathrm{H}_{2}\right)$ /oxygen $\left(\mathrm{O}_{2}\right)$ flames at 1 bar) to wall levels that are maintained in the $300-800 \mathrm{~K}$ range to avoid damaging. This high temperature variation occurs in a very thin layer, less than $1 \mathrm{~mm}$, leading to very strong temperature gradients and making experimental observation of FWI quite difficult.

\footnotetext{
* Corresponding author.

E-mail address: raphael.mari.cerfacs@gmail.com (R. Mari).
}

Ezekoye et al. [3] experimentally studied the impact of wall temperature and the equivalence ratio on the wall heat flux for propane and methane flames. It was shown that the maximum wall heat flux decreases when the wall temperature increases. Lu et al. [4] investigated FWI in the side wall quenching configuration where the flame propagates along the wall and found that the ratio of the wall heat flux to the heat release in the flame is roughly constant and equal to 0.3-0.4. Based on experimental correlations, Boust et al. [5] proposed a theoretical relation between the normalized wall heat flux and the quenching Peclet number, defined as the flame position normalized by the flame thickness, for methane-air flames where they observe that the wall heat flux is inversely proportional to the flame quenching distance.

Many numerical studies have been conducted on laminar flame-wall interactions [6-10]. It has been shown by Popp et al. [9] that in the low wall temperature regime $(300 \mathrm{~K}<$ $\left.T_{w}<400 \mathrm{~K}\right)$ the wall can be assumed chemically inert. Kim et al. [11] experimentally confirmed this result using several surface materials and wall temperatures. Dabireau et al. [7], Gruber et al. [12] and Owston et al. [10], demonstrated a strongly different behavior for hydrogen flames compared to hydrocarbon flames. Hydrogen flame quenching occurs much closer to the wall relatively to the flame thickness. Normalized wall heat flux is also largely different from hydrocarbon flames and equal to $\sim 0.12$. 
Nomenclature

\begin{tabular}{|c|c|c|}
\hline Symbol & Units & Description \\
\hline$C_{p}$ & $\mathrm{JK}^{-1} \mathrm{~kg}^{-1}$ & Heat capacity \\
\hline$D_{t h}$ & $\mathrm{~m}^{2} \mathrm{~s}^{-1}$ & Thermal diffusivity \\
\hline$e^{l i n}$ & $\mathrm{Jm}^{-2} \mathrm{~K}^{-1} \mathrm{~s}^{-1 / 2}$ & Effusivity \\
\hline$P_{c}$ & $\mathrm{~Pa}$ & Critical pressure \\
\hline $\mathrm{Pe}$ & - & Peclet number based on heat release rate \\
\hline$P e^{F}$ & - & Peclet number based on fuel consumption rate \\
\hline$Q$ & $\mathrm{Wm}^{-3}$ & Heat release rate \\
\hline$Q^{*}$ & - & Heat release rate non-dimensionalized with $Q_{1}^{0} / \delta$ \\
\hline$Q_{1}^{0}$ & $W m^{-2}$ & Laminar flame power \\
\hline$S_{1}^{0}$ & $\mathrm{~ms}^{-1}$ & Flame speed \\
\hline Sc & - & Schmidt number \\
\hline$T_{c}$ & K & Critical temperature \\
\hline$T_{S}$ & $\mathrm{~K}$ & Solid temperature \\
\hline$T_{w}$ & $\mathrm{~K}$ & Fluid-solid interface temperature \\
\hline$Z$ & - & Compressiblity factor \\
\hline \multicolumn{3}{|c|}{ Greek symbols } \\
\hline$\delta_{l}$ & $\mathrm{~m}$ & Thermal flame thickness \\
\hline$\delta$ & $\mathrm{m}$ & Diffusive flame thickness \\
\hline$\Delta H$ & $\mathrm{Jkg}^{-1}$ & Heat per $\mathrm{kg}$ of fuel \\
\hline$\kappa$ & - & Ratio of wall and fluid effusivities \\
\hline$\lambda$ & $\mathrm{W} \mathrm{m} \mathrm{m}^{-1} \mathrm{~K}^{-1}$ & Thermal conductivity \\
\hline$\Phi_{w}$ & $\mathrm{~W} \mathrm{~m}^{-2}$ & Heat flux \\
\hline$\Phi_{w}^{*}$ & - & Heat flux non-dimensionalized with $Q_{l}^{0}$ \\
\hline$\tau$ & $s$ & Flame characteristic time \\
\hline \multicolumn{3}{|c|}{ Superscripts } \\
\hline IFF & \multicolumn{2}{|c|}{ Infinitely Fast Flame } \\
\hline c & \multicolumn{2}{|c|}{ Coupled } \\
\hline U & \multicolumn{2}{|l|}{ Uncoupled } \\
\hline$b$ & \multicolumn{2}{|l|}{ burnt } \\
\hline$u$ & \multicolumn{2}{|l|}{ unburnt } \\
\hline \multicolumn{3}{|c|}{ Subscripts } \\
\hline Q & \multicolumn{2}{|l|}{ quenching } \\
\hline$w$ & \multicolumn{2}{|l|}{ wall } \\
\hline
\end{tabular}

In all these studies, results have been provided for wall boundary conditions either adiabatic or isothermal. However in reality heat transfer occurring between the solid wall and the fluid results in a possible increase of wall temperature and a non-zero heat flux, i.e. neither isothermal nor adiabatic wall behavior. In addition, the wall temperature is usually unknown and introduces a significant uncertainty on the predicted heat flux. Finally, FWI being a transient phenomenon, eventually leading to flame quenching, the solution cannot be searched for as a steady state solution and simulations describing the unsteady coupling of heat conduction in the wall with fluid dynamics and heat transfer are required [13]. Such approach avoids to impose the wall temperature at an arbitrary value, and allows it to adapt to the varying fluid temperature, consequently significantly modifying the wall heat flux.

To address this issue, the present study considers the unsteady behavior of a stoichiometric laminar one-dimensional premixed hydrogen-oxygen flame impinging on a cold wall including conjugate heat transfer. The context is liquid-fuel rocket engines (LREs), which operate at very low temperature and high pressure where the thermodynamic properties depart from ideal gas laws. Indeed, beyond the critical point, defined by $\left(P_{c}, T_{c}\right)$ values specific to each species, surface tension disappears and the distinction between gaseous and liquid phases vanishes. This state of matter is called supercritical, where phase change is replaced by a steep but continuous variation of the density and thermodynamic properties. Therefore the objective of the study is twofold: first, the role of conjugate heat transfer in FWI is studied; second, the impact on FWI of high pressure, up to supercritical conditions, is evaluated.

As shown in Fig. 1, the chosen configuration corresponds to head-on quenching (HOQ), where the flame propagates towards the wall with the characteristics of a free flame before interacting with the wall. In this simplified configuration in-depth analysis can be made and a good understanding of basic phenomena can be achieved. The HOQ configuration appears as a necessary first step

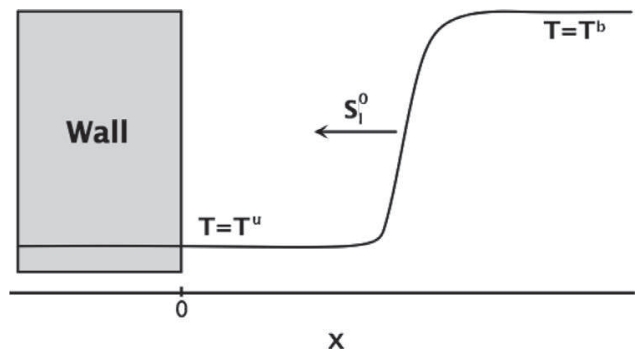

Fig. 1. Flame-wall interaction (FWI): head-on quenching (HOQ) configuration. Initial wall temperature $T_{w}^{i}$ is set equal to fresh gas temperature $T^{u}$.

to study both effects of high pressure and conjugate heat transfer prior to the thermal study of realistic configurations.

\section{Numerical setup and methodology}

Simulations were performed by running simultaneously a fluid (AVBP) and a thermal (AVTP) solver in a coupled framework. For comparison purposes, uncoupled simulations with an isothermal wall were also computed. In AVBP, the compressible reactive Navier-Stokes equations are solved with a third order in space and fourth order in time, two-steps Taylor-Galerkin scheme $[14,15]$ along with a second order Galerkin scheme for diffusion terms. The parallel conduction solver AVTP is based on the same data structure than AVBP and also uses a second order Galerkin diffusion scheme. Time integration is done with an implicit first order forward Euler scheme. The resolution of the implicit system is done with a parallel matrix free conjugate gradient method.

The coupling methodology consists in an exchange of variables at the wall surface between both codes: the fluid solver sends a heat flux and the heat conduction code sends back a temperature. Data are exchanged through a supervisor using OpenPalm libraries [16]. Between two coupling events, the flow and wall thermal conduction are advanced in time by a quantity $\alpha_{f} \tau_{f}$ and $\alpha_{w} \tau_{w}$ respectively, where $\tau_{f}$ and $\tau_{w}$ are the flow and heat conduction characteristic times. To respect simultaneity, the physical time computed by the codes must be the same between two data exchanges: $\alpha_{f} \tau_{f}=\alpha_{w} \tau_{w}$. This ensures continuity of the heat flux and temperature at the wall surface. More details and validation of the coupling methodology can be found in [17].

Computations were run on uniform grids, of similar grid spacing (see Table 4), in both the fluid and the solid. They were initialized with a free stationary premixed flame previously calculated under the same thermodynamic conditions (pressure and temperature), and located far enough from the wall to assume no interaction at the start of the simulation. For the same reason the initial wall temperature $T_{w}^{i}$ was taken equal to the fresh gas temperature $T^{u}$. The fluid boundary condition at the open end is a pressureimposed outlet, using the characteristic formulation for compressible flow [18]. The temperature is imposed at the left solid boundary to the initial wall temperature $T_{w}^{i}$. The solid is sufficiently long to ensure that this boundary condition does not influence FWI.

\section{Chemical kinetics}

Computations were carried out with a pure hydrogen $\left(\mathrm{H}_{2}\right)$ and pure oxygen $\left(\mathrm{O}_{2}\right)$ mixture at stoichiometry. The combustion of hydrogen and oxygen is modeled using a skeletal mechanism accounting for 8 species and 12 reactions from Boivin et al. [19], reported in Table 1. It is derived from the 21-step San Diego detailed mechanism [20], used in many hydrogen combustion applications. The so-called San Diego scheme has demonstrated its ability to 
a

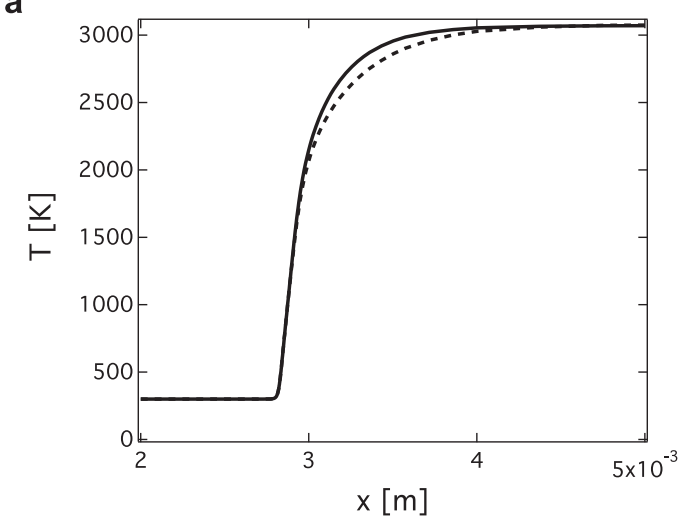

C

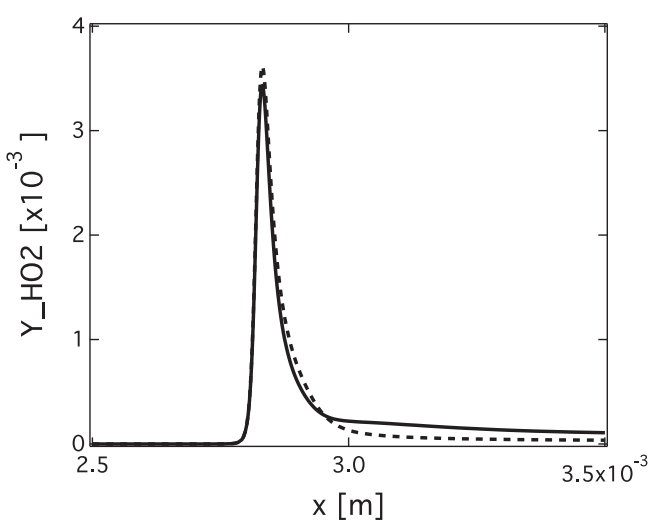

b

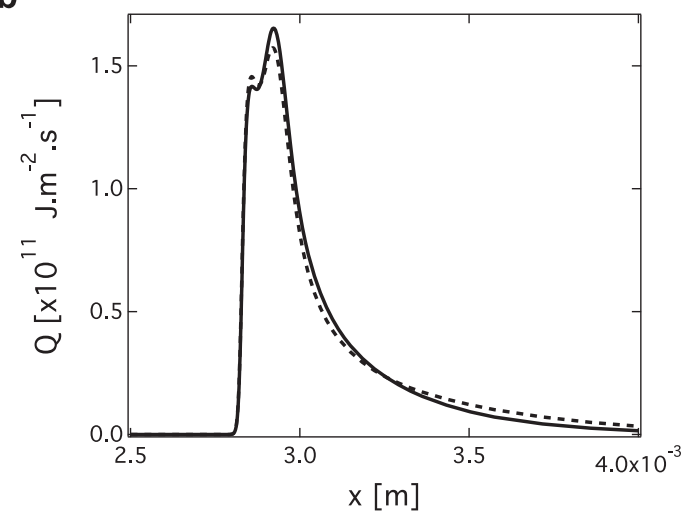

d

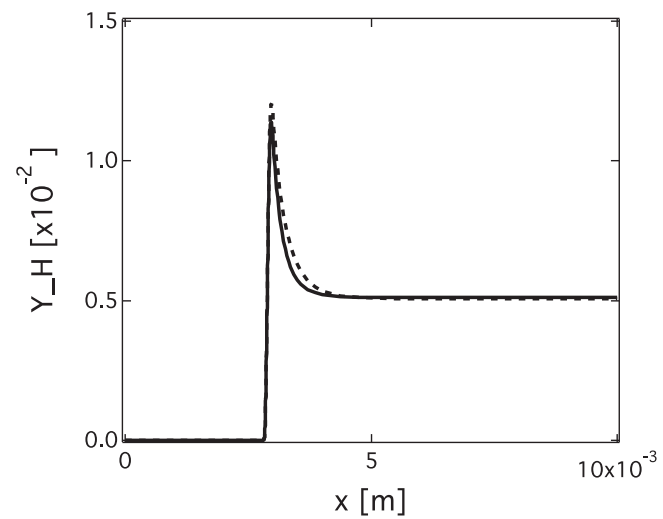

Fig. 2. 1D flame profiles of (a) temperature $T$, (b) heat release rate $Q$ (c) $\mathrm{HO}_{2}$ and (d) $\mathrm{H}$ mass fractions for (-) San Diego [20] and (- -) Boivin [19] mechanisms. Case 2a: pressure is 1 bar and fresh gas temperature $300 \mathrm{~K}$.

Table 1

Rate coefficients in Arrhenius form $k=A T^{n} \exp \left(-E / R^{0} T\right)$ as in [19].

\begin{tabular}{|c|c|c|c|c|c|}
\hline & Reaction & & $A^{\mathrm{a}}$ & $n$ & $E^{\mathrm{a}}$ \\
\hline \multirow[t]{2}{*}{ R1 } & $\mathrm{H}+\mathrm{O}_{2} \leftrightharpoons \mathrm{OH}+\mathrm{O}$ & $k_{f}$ & $3.5210^{16}$ & -0.7 & 71.42 \\
\hline & & $k_{b}$ & $7.0410^{13}$ & -0.26 & 0.60 \\
\hline \multirow[t]{2}{*}{ R2 } & $\mathrm{H}_{2}+\mathrm{O} \leftrightharpoons \mathrm{OH}+\mathrm{H}$ & $k_{f}$ & $5.0610^{4}$ & 2.67 & 26.32 \\
\hline & & $k_{b}$ & $3.0310^{4}$ & 2.63 & 20.23 \\
\hline \multirow[t]{2}{*}{ R3 } & $\mathrm{H}_{2}+\mathrm{OH} \leftrightharpoons \mathrm{H}_{2} \mathrm{O}+\mathrm{H}$ & $k_{f}$ & $1.1710^{9}$ & 1.3 & 15.21 \\
\hline & & $k_{b}$ & $1.2810^{10}$ & 1.19 & 78.25 \\
\hline \multirow[t]{2}{*}{ R4 } & $\mathrm{H}+\mathrm{O}_{2}+\mathrm{M} \rightarrow \mathrm{HO}_{2}+\mathrm{M}^{\mathrm{b}}$ & $k_{0}$ & $5.7510^{19}$ & -1.4 & 0.0 \\
\hline & & $k_{\infty}$ & $4.6510^{12}$ & 0.44 & 0.0 \\
\hline R5 & $\mathrm{HO}_{2}+\mathrm{H} \rightarrow 2 \mathrm{OH}$ & & $7.0810^{13}$ & 0.0 & 1.23 \\
\hline \multirow[t]{2}{*}{ R6 } & $\mathrm{HO}_{2}+\mathrm{OH} \leftrightharpoons \mathrm{H}_{2}+\mathrm{O}_{2}$ & $k_{f}$ & $1.6610^{13}$ & 0.0 & 3.44 \\
\hline & & $k_{b}$ & $2.6910^{12}$ & 0.36 & 231.86 \\
\hline R7 & $\mathrm{HO}_{2}+\mathrm{OH} \rightarrow \mathrm{H}_{2} \mathrm{O}+\mathrm{O}_{2}$ & & $2.8910^{13}$ & 0.0 & -2.08 \\
\hline \multirow[t]{2}{*}{ R8 } & $\mathrm{H}+\mathrm{OH}+\mathrm{M} \leftrightharpoons \mathrm{H}_{2} \mathrm{O}+\mathrm{M}^{\mathrm{c}}$ & $k_{f}$ & $4.0010^{22}$ & -2.0 & 0.0 \\
\hline & & $k_{b}$ & $1.0310^{23}$ & -1.75 & 496.14 \\
\hline \multirow[t]{2}{*}{ R9 } & $2 \mathrm{H}+\mathrm{M} \leftrightharpoons \mathrm{H}_{2}+\mathrm{M}^{\mathrm{c}}$ & $k_{f}$ & $1.3010^{18}$ & -1.0 & 0.0 \\
\hline & & $k_{b}$ & $3.0410^{17}$ & -0.65 & 433.09 \\
\hline R10 & $2 \mathrm{HO}_{2} \rightarrow \mathrm{H}_{2} \mathrm{O}_{2}+\mathrm{O}_{2}$ & & $3.0210^{12}$ & 0.0 & 5.8 \\
\hline R11 & $\mathrm{HO}_{2}+\mathrm{H}_{2} \rightarrow \mathrm{H}_{2} \mathrm{O}_{2}+\mathrm{H}$ & & $1.6210^{11}$ & 0.61 & 100.14 \\
\hline \multirow[t]{2}{*}{ R12 } & $\mathrm{H}_{2} \mathrm{O}_{2}+\mathrm{M} \rightarrow 2 \mathrm{OH}+\mathrm{M}^{\mathrm{d}}$ & $k_{0}$ & $8.1510^{23}$ & -1.9 & 207.62 \\
\hline & & $k_{\infty}$ & $2.6210^{19}$ & -1.39 & 214.74 \\
\hline
\end{tabular}

${ }^{a}$ Units are mol, $\mathrm{s}, \mathrm{cm}^{3}$, $\mathrm{kJ}$ and $\mathrm{K}$.

b Chaperon efficiencies $\mathrm{H}_{2}: 2.5, \mathrm{H}_{2} \mathrm{O}: 16.0,1.0$ for all other species. Troe falloff with $F_{c}=0.5$.

c Chaperon efficiencies $\mathrm{H}_{2}: 2.5, \mathrm{H}_{2} \mathrm{O}: 12.0,1.0$ for all other species.

d Chaperon efficiencies $\mathrm{H}_{2}: 2.5, \mathrm{H}_{2} \mathrm{O}: 6.0,1.0$ for all other species. Troe falloff with $F_{c}=0.265 \exp (-T / 94)+0.735 \exp (-T / 1756)+\exp (-T / 5182)$.

predict premixed flame speed, autoignition delay, burnt gases temperature and extinction limits under many conditions of pressure, temperature and composition [21] and is considered as a reference. In order to validate Boivin's scheme in the thermodynamic conditions of interest, i.e., fresh gas at $150 \mathrm{~K}, 300 \mathrm{~K}$ and $750 \mathrm{~K}$ and pres- sure up to 100 bar, premixed flames have been computed using CANTERA [22] and compared with the detailed mechanism. Results are shown here for flames corresponding to Cases $2 \mathrm{a}$ and $2 \mathrm{c}$ of Table 3. The stoichiometric laminar flame speeds obtained with the Boivin scheme $\left(10.76 \mathrm{~m} \mathrm{~s}^{-1}\right.$ and $9.03 \mathrm{~m} \mathrm{~s}^{-1}$, respectively) are very close to the values computed with the reference scheme of San Diego (10.61 $\mathrm{m} \mathrm{s}^{-1}$ and $9.46 \mathrm{~m} \mathrm{~s}^{-1}$, respectively). The flame structures shown in Figs. 2 and 3 demonstrate that both mechanisms are in very good agreement in terms of temperature, heat release rate, and species (including radicals) mass fraction profiles, at low and high pressure. In particular, the good prediction of species like $\mathrm{HO}_{2}$ is critical for FWI, as will be seen later. Similar results were obtained for the other cases conditions.

\section{Real-gas equations}

For high pressure computations, real-gas thermodynamics are accounted for through the Peng-Robinson equation of state [23] (PR-EOS). The general form of a cubic equation of state is given by:

$P(v, T)=\frac{R T}{v-b}-\frac{a(T)}{\left(v+\delta_{1} b\right)\left(v+\delta_{2} b\right)}$

where $P$ is the pressure, $T$ the temperature, $v$ the molar volume and $R$ the perfect-gas constant. The coefficients $a$ and $b$ account respectively for long-range and short-range interactions between molecules. In the Peng-Robinson equation the parameters $\left(\delta_{1}, \delta_{2}\right)$ are $(1+\sqrt{2}, 1-\sqrt{2})$. All thermodynamic coefficients must be modified to take into account real gas effects. At low pressure, a standard technique consists in tabulating or using polynomial fits to allow for the temperature dependence. This procedure can be 
a

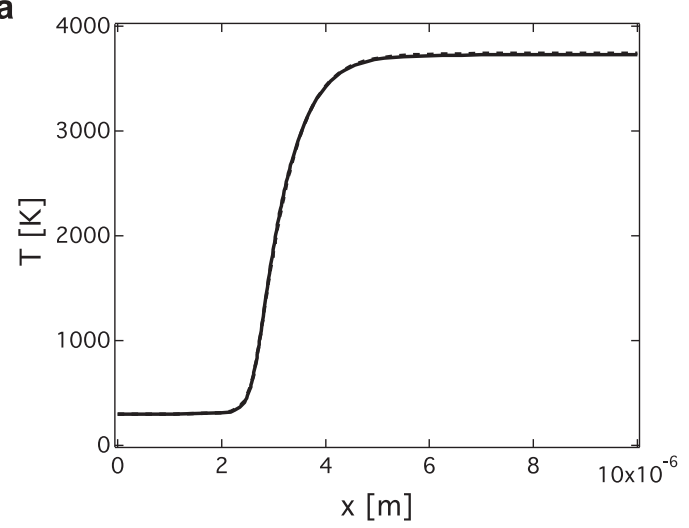

C

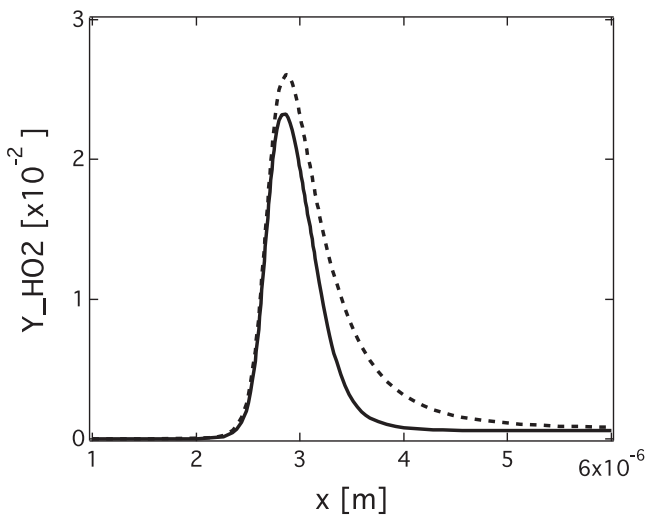

b

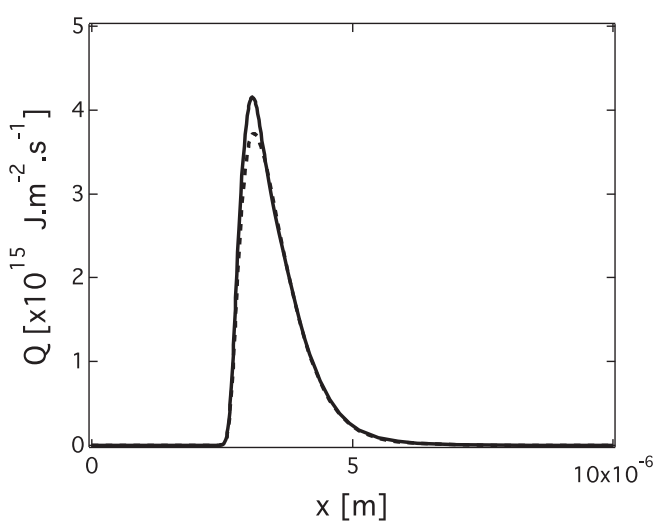

d

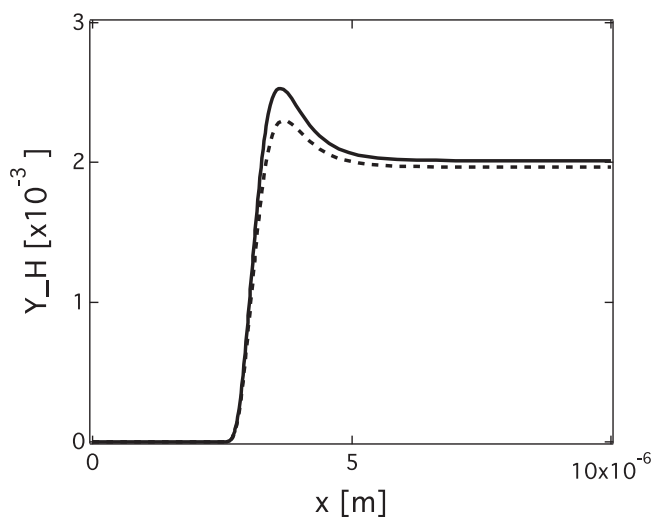

Fig. 3. $1 \mathrm{D}$ flame profiles of (a) temperature $T$, (b) heat release rate $Q$, (c) $\mathrm{HO}_{2}$ and (d) $\mathrm{H}$ mass fractions for (-) San Diego [20] and (- -) Boivin [19] mechanisms. Case 2c: pressure is 100 bar and fresh gas temperature $300 \mathrm{~K}$.

Table 2

Species critical-point temperature $T_{c}$ and pressure $P_{c}$, and Schmidt numbers.

\begin{tabular}{llclrrrrr}
\hline Parameters & $\mathrm{H}_{2}$ & \multicolumn{1}{c}{$\mathrm{O}_{2}$} & \multicolumn{1}{l}{$\mathrm{H}_{2} \mathrm{O}$} & \multicolumn{1}{l}{$\mathrm{O}$} & $\mathrm{H}$ & $\mathrm{OH}$ & $\mathrm{H}_{2} \mathrm{O}_{2}$ & $\mathrm{HO}_{2}$ \\
\hline$T_{c}[\mathrm{~K}]$ & 33 & 154.6 & 647.1 & 105.3 & 190.8 & 105.3 & 141.3 & 141.3 \\
$P_{c}[$ bar $]$ & 12.6 & 49.7 & 217.7 & 70.0 & 306.0 & 70.0 & 47.3 & 47.3 \\
$S c$ & 0.28 & 0.99 & 0.77 & 0.64 & 0.17 & 0.65 & 0.65 & 0.65 \\
\hline
\end{tabular}

extended to account for pressure dependence by keeping the tabulation for low pressure reference values and use departure functions based on the EOS to compute the influence of pressure [24]. For example to calculate the constant-pressure heat capacity $C_{p}$, one starts to write the Gibbs function $G$ as:

$G(P, T)=G_{0}+P v-R T+\int_{v}^{v_{0}} P(\bar{v}, T) d \bar{v}$

where $v_{0}$ and $G_{0}$ are respectively the molar volume and the Gibbs energy at a reference low pressure. The enthalpy $h$ is then classically defined as:

$h=G-T\left(\frac{\partial G}{\partial T}\right)_{P}$

as well as the constant-pressure heat capacity:

$C_{p}=\left(\frac{\partial h}{\partial T}\right)_{P}$

This points out that low-pressure data, combined with the PR-EOS, allow to compute all thermodynamic properties of the fluid at high pressure.

The viscosity and thermal conductivity are modeled following the method of Chung [25], based on the theory of corresponding states, linking low- and high-pressure values through semi-empirical functions expressed in reduced variables $T / T_{C}$ and
$P / P_{c}$. The low-pressure (ideal gas) reference values are computed from the Chapman-Enskog equation. Species diffusion velocities are expressed as functions of the species gradients using the Hirschfelder-Curtis approximation and constant Schmidt numbers $S_{c}$. It was indeed verified with detailed calculations using the software CANTERA [22], that in the considered cases the Schmidt numbers of most species do not strongly vary through the flame, and take the values reported in Table 2. Soret and Dufour effects are not included.

The critical point coordinates of the intermediate species $\mathrm{OH}$, $\mathrm{O}, \mathrm{H}, \mathrm{H}_{2} \mathrm{O}_{2}, \mathrm{HO}_{2}$ (for which no experimental values are available) are estimated as in [26], using the Lennard-Jones potentialwell depth, and the molecular diameter, taken from the transport database of the San Diego mechanism [20].

The ability of the AVBP solver to accurately reproduce supercritical and transcritical flows and flames has been demonstrated in various configurations corresponding to LRE conditions [27,28]. Note that real-gas thermodynamics also have an impact on the formulation of boundary conditions and Jacobian matrices of the numerical schemes.

\section{Flame wall interaction (FWI)}

Flame-wall interaction is first characterized with the wall heat flux, defined as the conductive flux evaluated at the wall: 
$\Phi_{w}=\left.\lambda_{w} \frac{\partial T}{\partial x}\right|_{w}$

where $\lambda_{w}$ is the thermal conductivity of the fluid evaluated at the wall. The wall heat flux is stronlgy linked to the flame characteristics: the thermal flame thickness $\delta_{l}$ is calculated from the temperature gradient:

$\delta_{l}=\frac{T^{b}-T^{u}}{(\nabla T)_{\max }}$

where $(\nabla T)_{\max }$ is the maximum of the temperature gradient. This flame thickness may be also estimated from the flame parameters using the diffusive flame thickness $\delta$ [7] given by:

$\delta=\frac{\lambda^{u}}{\rho^{u} C_{p}^{u} S_{l}^{0}}$

where $S_{l}^{0}$ is the laminar flame speed. The laminar flame power $Q_{l}^{0}$ is defined as:

$Q_{l}^{0}=\rho^{u} Y_{F}^{u} S_{l}^{0} \Delta \mathrm{H}$

where $Y_{F}^{u}$ is the fuel mass fraction in unburnt gases and $\Delta \mathrm{H}\left[\mathrm{J} \mathrm{kg}^{-1}\right]$ the heat produced per kilogram of fuel consumed.

The wall heat flux is non-dimensionalized by the flame power as $\Phi_{w}^{*}=\Phi_{w} / Q_{1}^{0}$, whereas the non-dimensional flame heat release rate is $Q^{*}=Q \delta / Q_{l}^{0}$. In addition, the flame characteristic time $\tau=$ $\delta / S_{l}^{0}$ is used to non-dimensionalize the time as $t^{*}=t / \tau$, while space dimensions are non-dimensionalized by the flame thickness as $x^{*}=x / \delta$.

Because of complex chemistry, the definition of the flame position is not unique. It can be either located at the maximum of heat release rate $Q_{\max }\left(x_{Q_{\max }}\right)$ or at the maximum of fuel consumption rate $\dot{\omega}_{F, \max }\left(x_{\dot{\omega}_{F, \max }}\right)$. Both locations are different and may be used to define Peclet numbers which characterize the ratio between diffusion and convective characteristic times:

- the heat release Peclet number is

$$
P e=\frac{x_{Q_{\max }}}{\delta}
$$

- the fuel Peclet number is

$$
P e^{F}=\frac{x_{\dot{\omega}_{F, \max }}}{\delta}
$$

Assuming that no reaction occurs at the wall, the temperature difference $T^{b}-T^{u}$ divided by the flame quenching distance gives an estimate of the wall temperature gradient. As shown in [5], this leads to a simple relationship between the non-dimensional wall heat flux and the Peclet number (either from the heat release or fuel consumption) $\Phi_{w}^{*} \sim 1 /$ Pe or, taking into account the wall heat loss:

$\Phi_{w}^{*} \sim 1 /(1+P e)$

Theoretical model: the infinitely fast flame model

The role and importance of the coupling between the solid and the fluid thermal problems may be understood from the limit case of infinitely fast flame [17] (IFF), in which the characteristic flame time scale is negligible compared to the solid conduction time. In this case the configuration reduces to the simpler problem of two semi-infinite domains having different temperatures and a common contact surface. Solving this classical heat transfer problem leads to the following expression for the interface temperature:

$T_{w}^{I F F}=\frac{e_{w} T_{w}+e_{f} T_{f}}{e_{w}+e_{f}}$

where $T_{w}\left(T_{f}\right)$ is the solid (resp. fluid) temperature, and $e_{w}\left(e_{f}\right)$ the solid (resp. fluid) effusivity defined by

$e=\sqrt{\lambda \rho C_{p}}$
Table 3

Summary of test cases: fresh gases properties at stoichiometry and compressibility factor calculated using NIST software REFPROP [30].

\begin{tabular}{lllll}
\hline Case & $\begin{array}{l}T^{u} \\
{[\mathrm{~K}]}\end{array}$ & $\begin{array}{l}\text { Pressure } \\
{[\mathrm{bar}]}\end{array}$ & $\begin{array}{l}\rho^{u} \\
{\left[\mathrm{~kg} \mathrm{~m}^{-3}\right]}\end{array}$ & $\begin{array}{l}\text { Compressibility factor } \\
\text { [Dimensionless] }\end{array}$ \\
\hline 1 & 750 & 1 & 0.1931 & 1.000 \\
$2 \mathrm{a}$ & & 1 & 0.4824 & 1.000 \\
$\mathrm{2b}$ & 300 & 10 & 4.8476 & 0.995 \\
$2 \mathrm{c}$ & & 100 & 48.342 & 0.998 \\
3 & 150 & 100 & 108.75 & 0.887 \\
\hline
\end{tabular}

where $\lambda$ is the heat conductivity, $\rho$ the density and $C_{p}$ the heat capacity of the solid $(w)$ or the fluid $(f)$.

Introducing the effusivity ratio parameter $\kappa=e_{w} / e_{f}$, Eq. (12) can be written

$T_{w}^{I F F}=\frac{\kappa T_{w}+T_{f}}{\kappa+1}$

Eq. (14) shows that the interface temperature depends on the parameter $\kappa$ : for large values of this ratio, the temperature at the solid/fluid interface stays close to the wall temperature and the wall may be considered isothermal; on the contrary, low values of $\kappa$ allow significant heating of the wall which is then neither isothermal nor adiabatic. In this last case the resolution of the unsteady coupled problem is necessary to obtain the correct wall heat flux.

\section{Cases description}

Several FWI cases for laminar stoichiometric premixed flames were performed and are summarized in Table 3. For all cases, the initial wall temperature $T_{w}^{i}$ and the fresh gas temperature $T^{u}$ are taken the same and non-coupled, isothermal simulations (denoted $U$ ) are compared to fluid-thermal solid coupled simulations (denoted ${ }^{C}$ ). Case 1 is presented for validation purposes and will be compared to previous studies $[7,10,12]$. Cases 2a, 2b and 2c allow to evaluate the influence of the pressure on FWI and extend the results to very high pressure. Finally Case 3 corresponds to cryogenic flames typical of LREs operating conditions, with very low fresh gas temperature.

The first effect of pressure increase is the reduction of the flame thickness, which may be approximated by a power law:

$\delta_{l}(P)=\delta_{l}\left(P_{0}\right)\left(\frac{P}{P_{0}}\right)^{\alpha}$

where $P_{0}$ is a reference pressure and $\alpha$ depends on the temperature and the fuel. In the case of stoichiometric hydrogen/oxygen mixture at $300 \mathrm{~K} \alpha \sim-1.21$ [29] was found, which means that the thermal flame thickness decreases with pressure. This a priori will have a strong impact on FWI, with an expected increase of wall heat flux with pressure.

As shown in Table 3, the fresh gas density $\rho^{u}$ increases drastically with increasing pressure and decreasing temperature, up to 200 times (Case 3) higher than the reference Case 2a at ambient conditions. Looking at the compressibility factor, given by:

$Z=\frac{P}{\rho r T}$

where $r$ is the specific gas constant, the deviation from the ideal gas law stays close to 1 as long as the temperature remains relatively high. For these cases no strong real gas effects are expected. With the decrease of the fresh gas temperature, Case 3 leads to a compressibility factor of 0.887 , i.e. presenting significant real gas effects. 


\begin{tabular}{|c|c|c|c|c|c|c|c|c|}
\hline Case & $\begin{array}{l}T^{u} \\
{[\mathrm{~K}]}\end{array}$ & $\begin{array}{l}P \\
{[\text { bar] }}\end{array}$ & $\begin{array}{l}T^{b}-T^{u} \\
{[\mathrm{~K}]}\end{array}$ & $\begin{array}{l}\mathrm{S}_{I}^{0} \\
{\left[\mathrm{~m} \mathrm{~s}^{-1}\right]}\end{array}$ & $\begin{array}{l}\delta_{l} \\
{[\mathrm{~m}]}\end{array}$ & $\begin{array}{l}\delta \\
{[\mathrm{m}]}\end{array}$ & $\begin{array}{l}Q_{l}^{0} \\
{\left[\mathrm{~W} \mathrm{~m}^{-2}\right]}\end{array}$ & $\begin{array}{l}\text { Mesh cell size } \\
{[\mathrm{m}]}\end{array}$ \\
\hline 1 & 750 & 1 & 2380 & 34.27 & $2.59 \mathrm{e}-4$ & $1.07 e-5$ & $8.66 \mathrm{e} 7$ & $2.0 \mathrm{e}-6$ \\
\hline $2 a$ & & 1 & 2770 & 10.76 & $2.23 e-4$ & $6.96 e-6$ & $6.87 \mathrm{e} 7$ & $2.0 \mathrm{e}-6$ \\
\hline $2 b$ & 300 & 10 & 3090 & 12.49 & $1.21 \mathrm{e}-5$ & $5.85 e-7$ & $8.22 \mathrm{e} 8$ & $2.0 \mathrm{e}-7$ \\
\hline $2 c$ & & 100 & 3430 & 9.03 & $1.18 \mathrm{e}-6$ & $9.46 e-8$ & $6.25 \mathrm{e} 9$ & $1.0 \mathrm{e}-8$ \\
\hline 3 & 150 & 100 & 3544 & 3.96 & $1.23 \mathrm{e}-6$ & $5.93 e-8$ & $5.47 \mathrm{e} 9$ & $1.0 \mathrm{e}-8$ \\
\hline
\end{tabular}

Table 5

Fluid and wall thermal effusivity, effusivity ratio $\kappa$ and interface temperature predicted by the IFF

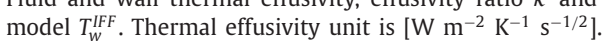

\begin{tabular}{lllllll}
\hline Case & $\begin{array}{l}T_{w}^{i} \\
{[\mathrm{~K}]}\end{array}$ & $\begin{array}{l}\text { Pressure } \\
{[\mathrm{bar}]}\end{array}$ & $\begin{array}{l}\text { Fluid effusivity } e_{f} \\
{[\mathrm{SI}]}\end{array}$ & $\begin{array}{l}\text { Wall effusivity } e_{w} \\
{[\mathrm{SI}]}\end{array}$ & $\begin{array}{l}\kappa \\
{[\text { Dimensionless }]}\end{array}$ & $\begin{array}{l}\mathrm{T}_{w}^{I F F} \\
{[\mathrm{~K}]}\end{array}$ \\
\hline 1 & 750 & 1 & 6.09 & 9280 & 1524 & 751.6 \\
& & 1 & 4.47 & 6186 & 1383 & 302 \\
$2 \mathrm{a}$ & \multirow{2}{*}{300} & 10 & 13.92 & 6186 & 444 & 307 \\
$2 \mathrm{c}$ & & 100 & 96.61 & 6186 & 64 & 352.8 \\
3 & 150 & 100 & 93.62 & 4914 & 52.5 & 216.2 \\
\hline
\end{tabular}


Fig. 4. Comparison of $\mathrm{H}_{2} \mathrm{O}_{2}$ (left) and $\mathrm{HO}_{2}$ (right) profiles in free propagating flames between Case 2c (solid line) and Case 3 (dashed line).

Flame properties, computed with the Boivin scheme, are shown in Table 4 for the various cases, together with the mesh resolution. The temperature difference $T^{b}-T^{u}$ and flame thickness change largely when the pressure increases, from $2770 \mathrm{~K}$ and $223 \mu \mathrm{m}$ for Case $2 \mathrm{a}$ to $3430 \mathrm{~K}$ and $1.18 \mu \mathrm{m}$ for Case $2 \mathrm{c}$. The flame thickness has a direct consequence on the mesh cell size that is changed accordingly to resolve the flame front.

The flame speed first increases with pressure, until $\sim 15 \mathrm{bar}$, where it reaches $\sim 12.5 \mathrm{~m} \mathrm{~s}^{-1}$, before decreasing for higher pressure, to reach $\sim 9.0 \mathrm{~m} \mathrm{~s}^{-1}$. This non-monotonic behavior was already shown in [31] and is due to the change of chain-branching to straight-chain kinetics. The flame speed also increases with the fresh gas temperature $T^{u}$, which has a direct effect on the chemistry but also modifies the thermal diffusivity $D_{t h}^{u}=\lambda^{u} / \rho^{u} C p^{u}$. Increasing the fresh gas temperature at ambient pressure leads to a strong increase of the flame velocity and moderate change of burnt gas temperature and flame thickness (Case 1). Finally the cryogenic condition (Case 3 ) gives a hot but slow flame. Its structure is detailed below.

\subsection{Cryogenic premixed flame}

The cryogenic, supercritical flame (Case 3) exhibits a particular structure. When compared to Case $2 c$, the first impact of the lower temperature, amplified by the real gas thermodynamics, is to significantly increase the density in the fresh gas, from $48 \mathrm{~kg} \mathrm{~m}^{-3}$
(Case 2c) to $108 \mathrm{~kg} \mathrm{~m}^{-3}$ (Case 3), while the burnt gas temperature is only slightly lower. The important decrease of the laminar flame speed is mostly related to the decrease of the thermal diffusivity $D_{t h}^{u}$, from $9.2610^{-7} \mathrm{~m}^{2} \mathrm{~s}^{-1}$ in Case $2 \mathrm{c}$ to $2.2310^{-7} \mathrm{~m}^{2} \mathrm{~s}^{-1}$ in Case 3, associated to supercritical transport properties. The most remarkable feature of Case 3 is the change of the chemical structure in the induction zone ahead of the flame. Figure 4 shows $\mathrm{HO}_{2}$ and $\mathrm{H}_{2} \mathrm{O}_{2}$ mass fraction profiles for Cases $2 \mathrm{c}$ and 3 . As already observed in many studies $[6,7,12]$, premixed flames are characterized by chemical reactions occurring in the induction zone between reactants and radical species that diffuse from the main reaction zone. In the case of $\mathrm{H}_{2} / \mathrm{O}_{2}$ flames, these reactions lead to the formation of $\mathrm{HO}_{2}$ and $\mathrm{H}_{2} \mathrm{O}_{2}$ in the induction zone. In Case 3, real gas transport strongly limits radical diffusion, so that even zero-activation, recombination reactions such as $\mathrm{R} 4$, R8 or R9 of Table 1 cannot occur. As a consequence, radical species do not appear in the induction zone in Case 3, as clearly visible in Fig. 4. Cryogenic, supercritical flames therefore have no reactive induction zone and all reactions start simultaneously when the temperature reaches a sufficiently high value. This will have direct consequences on the flame-wall interaction for these flames.

Table 5 summarizes the fluid and wall effusivities for all test cases. Both quantities increase with temperature, but $e_{f}$ increases even more strongly with pressure. The resulting interface temperatures predicted by the IFF model, where the wall temperature has been taken to the initial wall temperature $T_{w}^{i}=T^{u}$ and the 

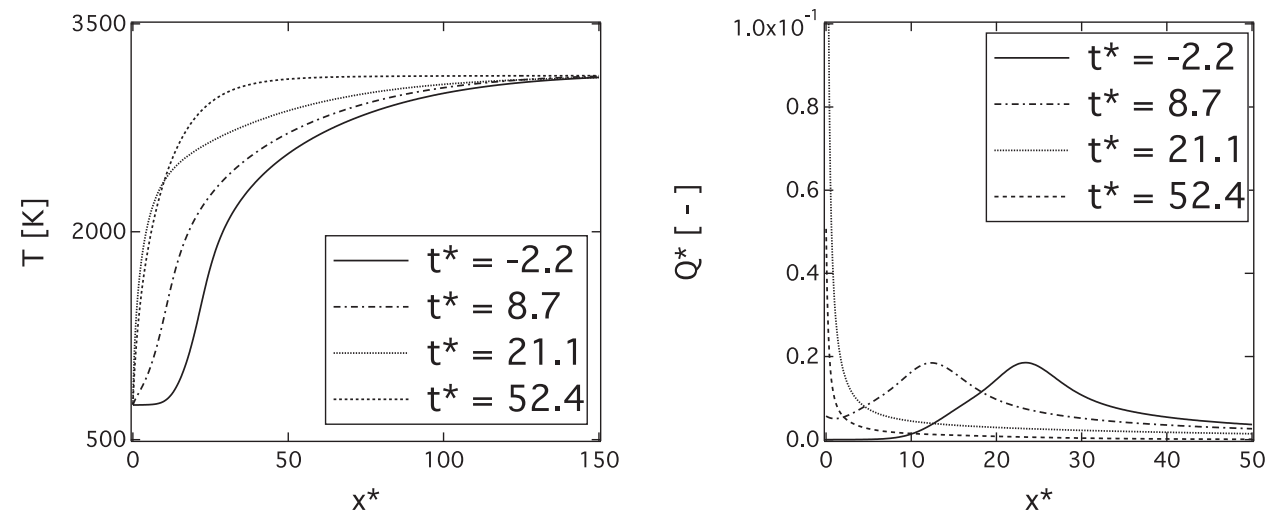

Fig. 5. Profiles of temperature (left) and dimensionless heat release rate (right) at various instants of FWI. Maximum non-dimensional heat release rate is 0.352. Case 1, coupled.
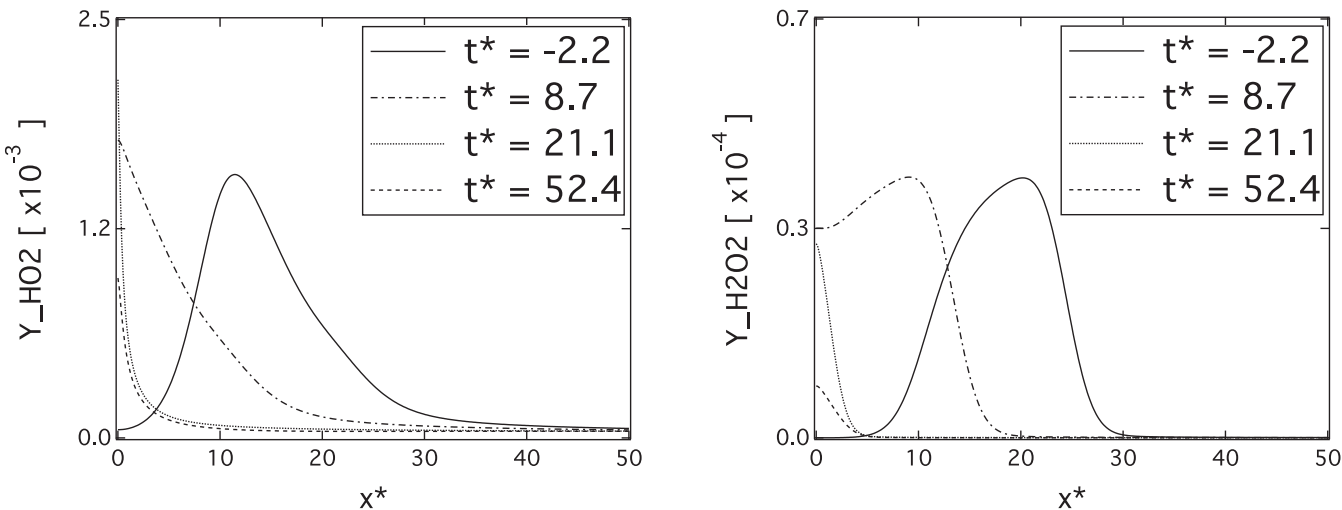

Fig. 6. Profiles of $\mathrm{HO}_{2}$ (left) and $\mathrm{H}_{2} \mathrm{O}_{2}$ (right) mass fractions at various instants of FWI. Case 1 , coupled.

fluid temperature has been taken to the burnt gas temperature $T^{b}$, stays close to the initial interface temperature for high values of $\kappa$, in Cases 1 and 2a. As the fluid thermal effusivity increases from Cases $2 \mathrm{a}$ to $2 \mathrm{c}$, the ratio $\kappa$ decreases and the final wall temperature moves away from the initial temperature. Finally Cases $2 \mathrm{c}$ and 3 , with low $\kappa$, show a significant wall temperature increase.

\section{Results and discussion}

\subsection{Validation case 1}

Case 1 is first presented for validation purposes, as it is close to the isothermal wall case studied in previous publications $[7,10,12]$. Indeed in this case the high effusivity ratio $\kappa=1524$ leads to a theoretical wall temperature $T_{w}^{I F F}=751.6 \mathrm{~K}$, very close to the initial wall temperature, so that the isothermal wall assumption is fully valid, and no strong differences with the coupled solution are expected. Figure 5 (left) shows the temperature profiles at several instants, illustrating the time-dependency of FWI and the quenching process. To allow comparison between cases, time is set to 0 at the start of FWI, i.e., when the wall heat flux starts to increase. As a consequence the flame first propagates freely towards the wall, keeping a free flame structure until $t^{*} \sim 0$. Then the flame starts to interact with the wall, and becomes thinner while approaching the wall until $t^{*} \sim 20$. At this time, there is no sufficient remaining fuel in the cold gas and the flame quenches. In the same time, a transient process occurs from the start of FWI, where a very large increase of the heat release rate at the wall is observed (Fig. 5 (right)). This is linked to a change of the chemical behavior of the induction zone when approaching the wall. In freely propa- gating flames, preliminary decomposition of the fuel occurs in the induction zone through high-energy-activation reactions with radicals such as $R 2$ and $R 3$ (Table 1 ). During FWI, the temperature in the induction zone decreases down to the wall temperature and these reactions get frozen, leading to a longer persistence of $\mathrm{O}_{2}$ than $\mathrm{H}_{2}$ near the wall. At the same time, and for the same reason, zero-activation-energy, exothermic, radical recombination reactions such as $R 4$ and $R 8$ become dominant, and lead to the observed peak of heat release rate and production rate of $\mathrm{HO}_{2}$ (Fig. 6 (left)). Hence, through the low-activation-energy, propagation reaction $R 10$ hydrogen peroxide $\left(\mathrm{H}_{2} \mathrm{O}_{2}\right)$ is also produced (Fig. 6 (right)). All these chemical mechanisms were already observed in isothermal FWI $[7,10,12]$. By increasing the wall temperature gradient, this strong peak of heat release at the wall has a direct impact on the wall heat flux. In addition, it leads to a zero quenching distance which can therefore not be used to evaluate the heat flux as in Eq. (11).

Figure 7 (left) shows the time evolution of the wall heat flux and wall temperature during FWI. The wall temperature progressively increases to a value of $755.5 \mathrm{~K}$, i.e., slightly higher than the IFF model value of $751.6 \mathrm{~K}$. The maximum wall heat flux is obtained when the flame quenches at $t^{*} \sim 18$, and reaches $\Phi_{w, Q}=$ $18.9 \mathrm{MW} \mathrm{m}^{-2}\left(\Phi_{w, Q}^{*}=0.218\right)$. After flame quenching, the wall heat flux experiences first a fast decrease, then a much slower decrease $\left(\propto 1 / \sqrt{t^{*}}\right)$ corresponding to the heat diffusion in the fluid and in the solid. During FWI, the flame propagates toward the wall until the remaining fuel is too low to sustain the flame and compensate for the wall heat loss. The fuel quenching distance is therefore mainly controlled by the flame power and the wall temperature. In the present case, the fuel Peclet number at quenching is found $P e_{Q}^{F}=1.4$, as illustrated in Fig. 7 (right) showing the time 

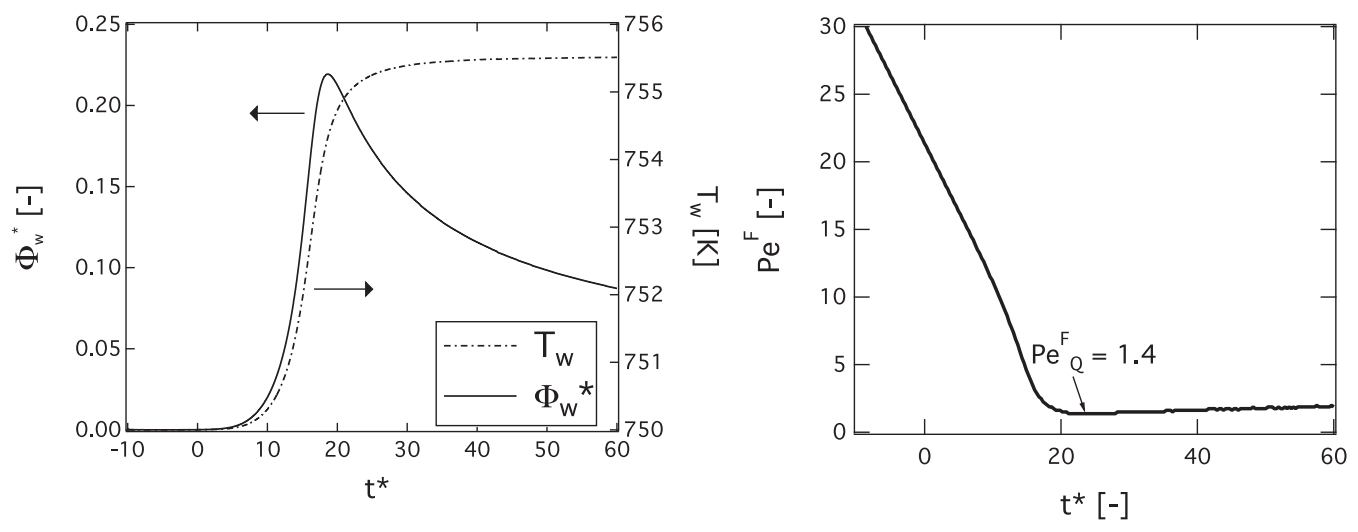

Fig. 7. Temporal evolution of (left) wall heat flux and wall temperature and (right) fuel Peclet number. Case 1, coupled.

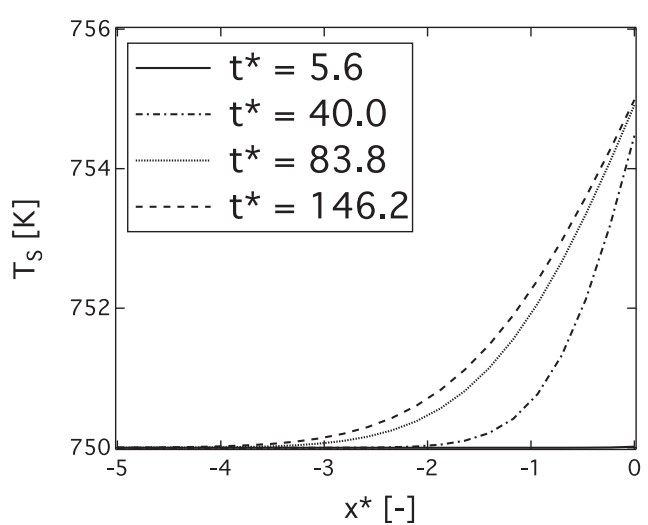

Fig. 8. Time evolution of temperature profiles in the solid wall $T_{S}$. Case 1 , coupled.

evolution of the fuel Peclet number during FWI. Both the nondimensional flux and the quenching fuel Peclet number are smaller than usual values obtained in FWI ( $\sim 0.3$ and $\sim 3.0$ respectively) and may be explained by the high wall temperature. The decrease of the maximum wall heat flux with increasing wall temperature was also described in [3]. This may be enhanced by the high diffusivity of $\mathrm{H}_{2}$ and the high heat release at the wall due to radical recombination as already mentioned. This trend and the values of the wall heat flux and quenching distance obtained in Case 1 are in good agreement with the results of $[7,12]$ or [10] where a maximum wall heat flux $\sim 18 \mathrm{MW} \mathrm{m}^{-2}$ was found for the same case.

Finally, Fig. 8 shows the temporal evolution of the temperature in the solid wall. One can observe that the coupling methodology is able to transfer the heat flux to the wall, which then diffuses in the solid. Note that the heat penetration is much slower in the solid than in the fluid, which is consistent with the higher solid effusivity.

\subsection{Effect of pressure}

In this section the effect of pressure on FWI is investigated with Cases 2a (1 bar) to 2c (100 bar). Although Case 2c is at high pressure, the relatively high temperature leads to a compressibility factor close to 1 and no real gas effects are expected here. From the above IFF analysis, results are expected to be comparable to those obtained in FWI with an isothermal wall for Cases 2a and 2b. Indeed, the IFF interface temperature does not exceed the initial wall temperature by more than $2 \mathrm{~K}$ and $7 \mathrm{~K}$, respectively. In Case $2 \mathrm{c}$ however, the burnt gas effusivity $e_{f}=96.6 \mathrm{~W} \mathrm{~m}^{-2} \mathrm{~K}^{-1} \mathrm{~s}^{-1 / 2}$ being much higher, the predicted interface temperature increases up to

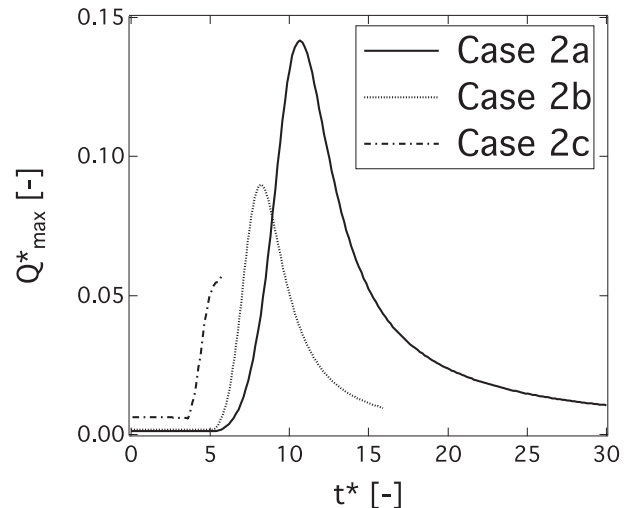

Fig. 9. Temporal evolution of the non-dimensional maximum heat release at the wall for Cases 2a, 2b and 2c, coupled. For all cases, time is set to 0 at the start of FWI.

$T_{w}^{I F F}=352 \mathrm{~K}$ and the coupled simulation is expected to give significantly different results from the corresponding isothermal FWI.

Overall, similar trends as in the validation case are observed, with a heat release peak and production of $\mathrm{H}_{2} \mathrm{O}_{2}$ and $\mathrm{HO}_{2}$ radicals occurring at the wall during the FWI. However, as the wall temperature is smaller, the effect is significantly amplified in comparison to Case 1 . Indeed the non-dimensional maximum heat release, shown in Fig. 9 is about 2 orders of magnitude larger during FWI than in the free flame in Case 2a, whereas it was only one order of magnitude larger in Case 1 (Fig. 5 (right)). The effect is however decreasing with pressure, coming back in Case $2 \mathrm{c}$ to the same order of magnitude than in Case 1.

Figure 10 shows the temporal evolution of the non-dimensional heat flux and the temperature at the wall for the three cases. Due to faster chemistry and smaller flame thickness, FWI is faster at high pressure. The maximum wall heat flux is obtained when flame quenches at $t^{*} \sim 11, t^{*} \sim 8$ and $t^{*} \sim 5$ for Cases $2 \mathrm{a}, 2 \mathrm{~b}$ and $2 \mathrm{c}$ respectively, and slightly decreases with pressure, from $\Phi_{w, Q}^{*}=0.388$ for Case $2 \mathrm{a}$ to $\Phi_{w, Q}^{*}=0.333$ for Case 2 c, consistently with the lower wall heat release effect at high pressure. Overall, the maximum wall heat flux is little sensitive to pressure and stays in the range $0.3-0.4$, i.e., similar to hydrocarbon flames with low wall temperatures $[4,32,33]$. Note however that the dimensional wall heat flux increases with pressure, from $\Phi_{w, Q}=26.4 \mathrm{MW} \mathrm{m}^{-2}$ for Case 2a to $\Phi_{w, Q}=2.09 \mathrm{GW} \mathrm{m}^{-2}$ for Case $2 c$, i.e., reaching extremely high values.

As expected from the IFF model, the interface temperature increases only slightly at low pressure (Cases $2 \mathrm{a}$ and $2 \mathrm{~b}$ ), but reaches a much higher value of $545 \mathrm{~K}$ for the high pressure Case $2 \mathrm{c}$. Note 

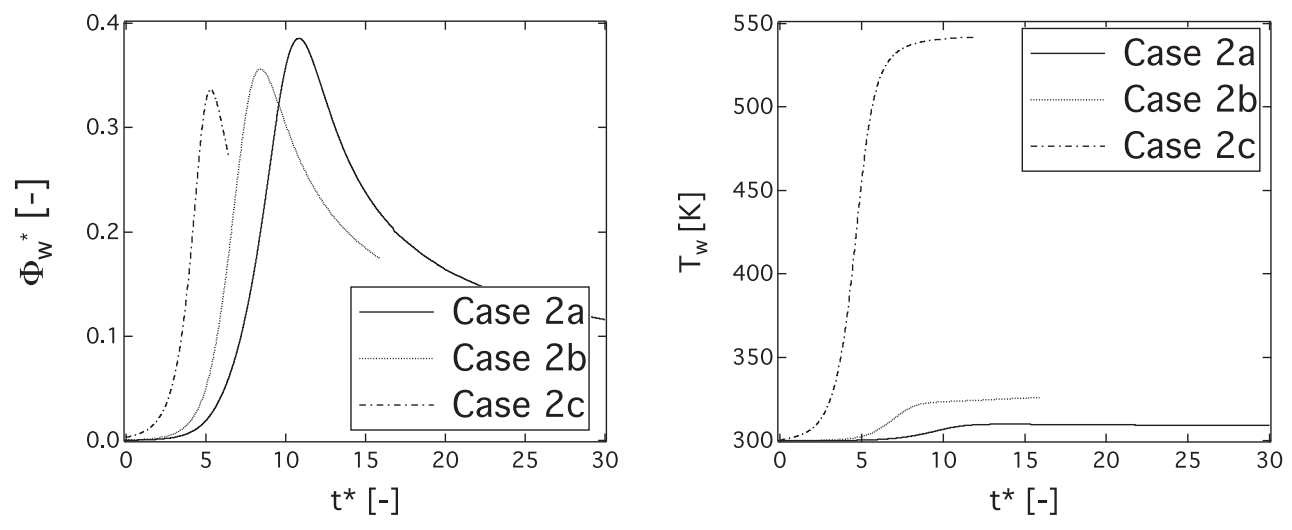

Fig. 10. Temporal evolution of non-dimensional wall heat flux (left) and wall temperature (right). Cases $2 a, 2 b, 2 c$, coupled.

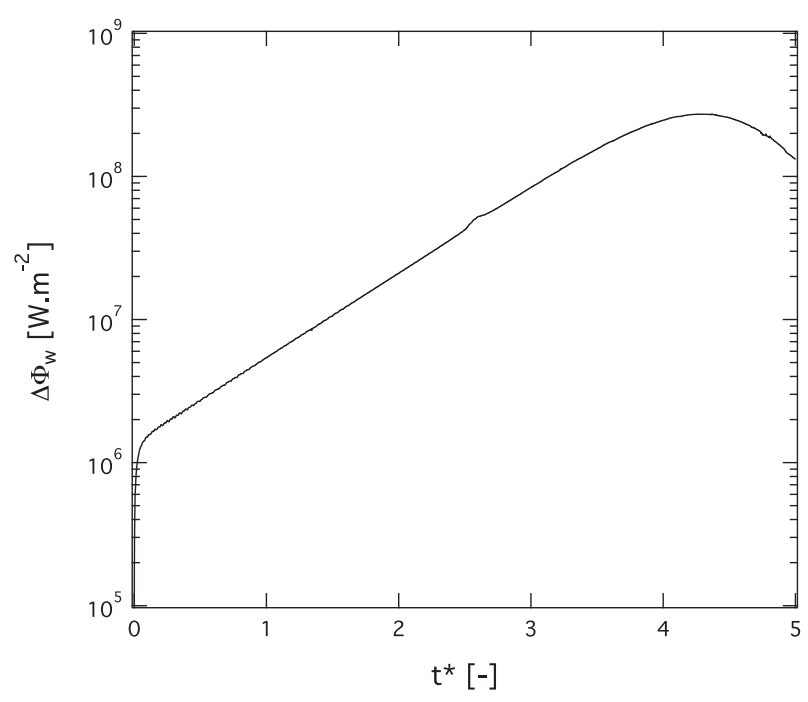

Fig. 11. Time evolution of wall heat flux difference $\Delta \Phi_{w}=\Phi_{w}^{U}-\Phi_{w}^{C}$ between isothermal wall condition and coupled computation. Case 2c. $\Phi_{w}^{C}=2.09 e 9 \mathrm{~W} \mathrm{~m}^{-2}$.

that the increase is always stronger than predicted by the IFF model. This difference is due to the strong heat release, both in the flame and at the wall, during FWI in the coupled simulations and which is not taken into account in the IFF model. This makes the heat flux stronger and increases the interface temperature. This justifies a posteriori the use of fully coupled simulations for the prediction of heat transfer.

The interface temperature increase also explains the wall heat flux decrease with pressure. Figure 11 shows the evolution of the difference between the wall heat flux obtained in the uncoupled (calculated with an isothermal wall condition at $T_{w}=300 \mathrm{~K}$ ) $\Phi_{w}^{U}$ and the coupled computation $\Phi_{w}^{C}$ of Case 2c. The maximum difference is observed just before quenching, where the isothermal wall assumption leads to an overestimation of the maximal wall heat flux by $200 \mathrm{MW} \mathrm{m}^{-2}$, i.e., approximately $10 \%$ of the wall heat flux in the coupled case, which is significant for the thermal fatigue of solid materials. This corresponds to a non-dimensional wall heat flux of $\Phi_{w, Q}^{U *}=0.352$, i.e., closer to the low pressure cases than the coupled case.

Figure 12 (left) shows the fuel Peclet number obtained at quenching for the three cases. The quenching distance of $P e_{Q}^{F}=4.1$ for Case 2a is larger than for Case 1 due to the lower wall temperature. It is slightly larger than the value of $\sim 3$ typically observed in previous numerical and experimental studies for hydrocarbons fuels $[4,32,33]$, which may be due to the high diffusivity of
$\mathrm{H}_{2}$. When pressure increases, the quenching distance slightly decreases, down to $P e_{Q}^{F}=3.2$ for Case $2 c$, still staying in the range $3-4$. The slight decrease of $P e_{Q}^{F}$ with pressure may be again attributed to the increase of the interface temperature which allows fuel oxidation reactions to occur closer to the wall. As already mentioned, the non-dimensional maximum wall heat flux, also reported in Fig. 12 (right), decreases with pressure. This behavior was already observed in other studies $[5,34]$ for lower pressure ranges (0.5-3.5 bar) and is confirmed here for higher pressure levels and conjugate heat transfer. This also demonstrates that, although the simple expression Eq. (11) still holds in terms of order of magnitude, it is not able to describe a complex behavior such as the simultaneous decrease of both $\Phi_{w, Q}^{*}$ and $P e_{0}^{F}$ with increasing pressure. This indeed is the result of chemical phenomena occuring at the wall and cannot be predicted from free flame parameters such as the flame thickness $\delta_{l}$.

\subsection{Supercritical case}

This section presents the results obtained for the supercritical case (Case 3) where the fresh gas temperature has been lowered down to $T^{u}=150 \mathrm{~K}$. The compressibility factor in that case is 0.887 meaning that real gas effects have to be taken into account. As shown in Table 5, the effusivity of the burnt gas is large in such thermodynamic conditions, thus requiring the fluid/solid thermal coupling to simulate the transient FWI and predict the final wall temperature. FWI with an isothermal wall at $150 \mathrm{~K}$ leads to strong water condensation when the combustion products reach the wall, so that direct comparison of coupled or uncoupled cases is not possible in this case.

Figure 13 (left) reports the temperature profiles during FWI. The overall process is similar to all previous cases and is comparable to Case 2c, also at high pressure. As in Case 2c, the interaction is quite fast, with quenching occurring at $t^{*} \sim 8$, and heat release peak on the wall is still observed (Fig. 13 (right)). However as was observed in the cryogenic free flame, the induction zone is frozen due to the low temperature and does not interact with the wall. Neither $\mathrm{H}_{2} \mathrm{O}_{2}$ or $\mathrm{HO}_{2}$ are present outside the flame zone and they start to build on the wall only when the flame reaches the wall. Compared to Case 2c, the increase of heat release at the wall is delayed and starts shortly before quenching. As a result, although the increase is comparable to Case $2 c$, its impact on the wall heat flux is reduced.

In supercritical conditions, the fluid properties differ largely from the perfect gas, with a thermal diffusivity divided by 4 when compared to Case 2c. (Case 2c: $\lambda^{u} / \rho^{u} C p^{u}=9.2610^{-7} \mathrm{~m}^{2} \mathrm{~s}^{-1}$ and Case $\left.3: \lambda^{u} / \rho^{u} C_{p}^{u}=2.2310^{-7} \mathrm{~m}^{2} \mathrm{~s}^{-1}\right)$. This, combined with the low fresh gas temperature, leads to a large quenching distance 

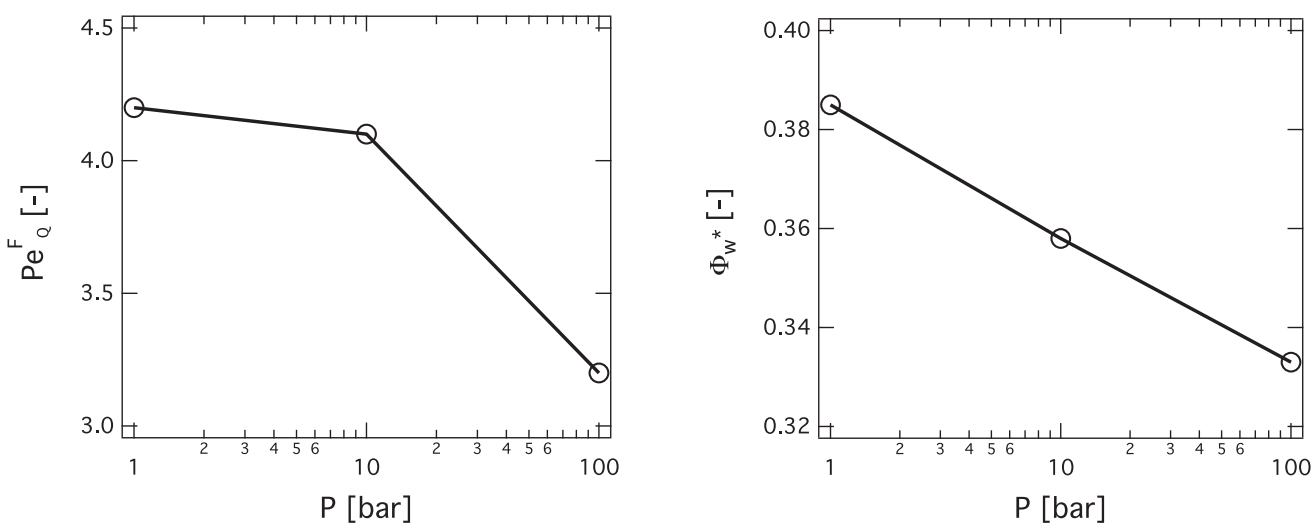

Fig. 12. Effect of pressure on the quenching fuel Peclet number $P e_{Q}^{F}(\circ)$ (left) and on the dimensionless maximum wall heat flux $\Phi_{w, Q}^{*}(\circ)$ (right) for Cases 2 a,b,c, coupled simulations.
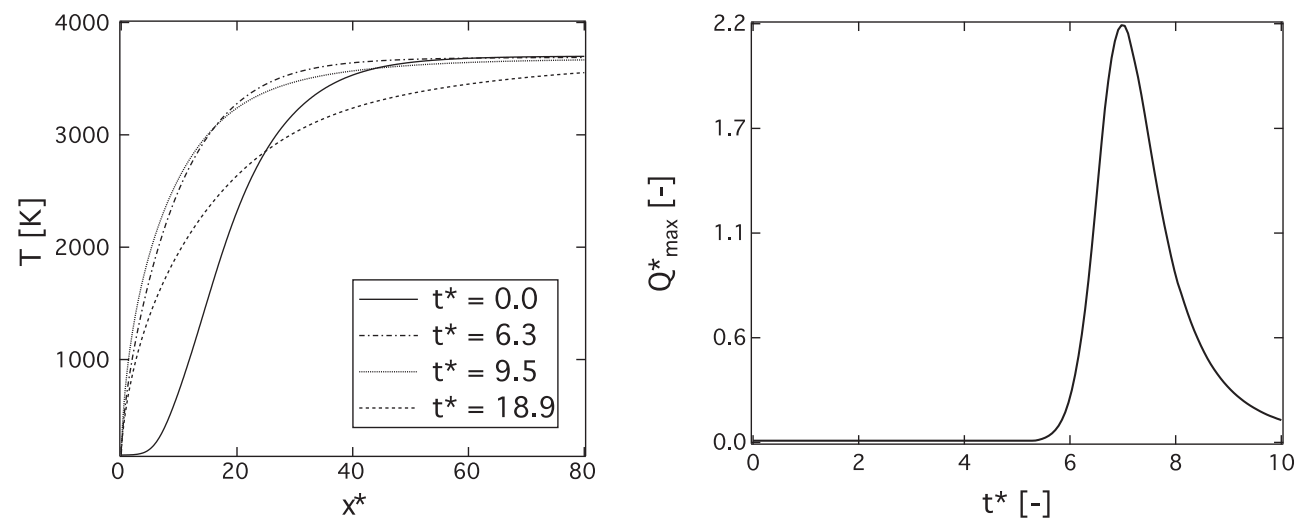

Fig. 13. Profiles of temperature at various instants of FWI (left) and time evolution of the maximum heat release at the wall (right). Case 3 , coupled.

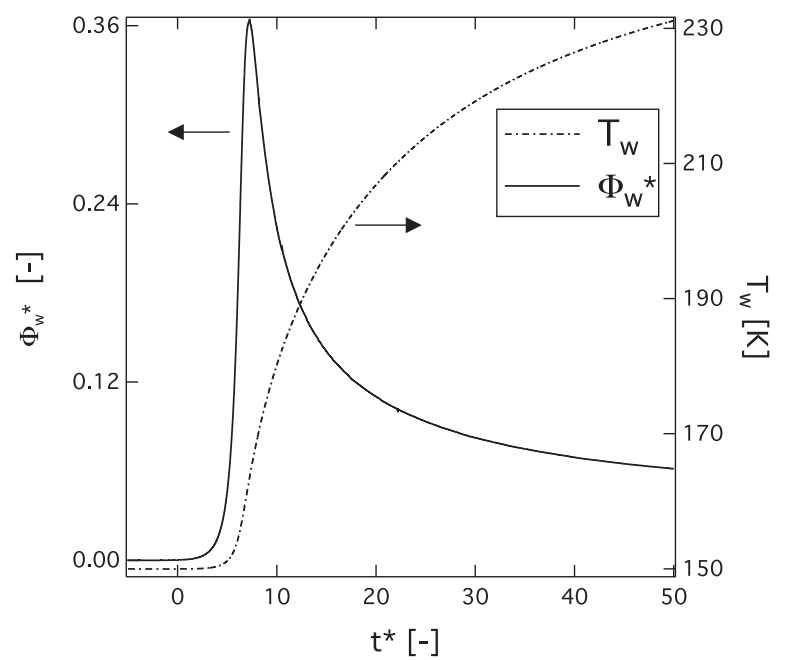

Fig. 14. Temporal evolution of wall heat flux and wall temperature. Case 3, coupled.

corresponding to $P e_{Q}^{F}=6.0$. As a consequence, the wall temperature increases slowly, remaining low during the quenching process and still increasing after the flame has extinguished (Fig. 14). As the heat release at the wall stays zero for a long time and starts to increase just before quenching, it does not contribute much to the wall temperature increase which stays close to the predicted IFF temperature $\left(T_{w}^{I F F}=216.2 \mathrm{~K}\right)$. The non-dimensional maximum wall heat flux reaches a value of $0.36\left(\Phi_{w, Q}=1.97 \mathrm{GW} \mathrm{m}^{-2}\right)$, i.e., stays in the range $0.3-0.4$, mainly thanks to the large temperature difference $T^{b}-T^{u}$. In this case, Eq. (11) does not hold anymore. This again demonstrates that the quenching distance and the maximum wall heat flux are not directly linked but strongly depend on the interface temperature, requiring the use of coupled simulations.

\section{Conclusions}

The interaction between premixed flames and non-adiabatic walls has been investigated in a conjugate heat transfer approach, where the fluid and the solid wall are thermally coupled. To be representative of liquid rocket engines, stoichiometric $\mathrm{H}_{2}-\mathrm{O}_{2}$ mixtures in ambient and cryogenic (low temperature, high pressure) conditions have been considered. A unique framework, coupling both fluid and heat transfer solvers, was used in order to take into account the wall heating transient phenomena. It was demonstrated that if the effusivity of the burnt gas becomes nonnegligible compared to that of the solid, the isothermal assumption does not hold anymore. It was found that this situation mainly occurs at high pressure, requiring the use of fluid-solid thermal coupling. When pressure increases, the more powerful and much thinner flame leads to important quenching distance decrease and maximum wall heat flux increase by two orders of magnitude compared to atmospheric conditions. However, when non-dimensionalized with the flame thickness and flame power, both quantities become almost insensitive to pressure and take typical values already observed in hydrocarbon flames. Still, the increase of wall temperature due to conjugate heat transfer, and the heat release at the wall due to radical recombination, are responsible for a slight decrease of the quenching distance and maximum wall heat flux when pressure increases. Finally, low-temperature, high-pressure cryogenic conditions which lead to supercritical fluid properties and the vanishing of the induction zone, give a very 
large quenching distance. However the non-dimensional maximum wall heat flux stays comparable to the previous cases. In this case also, significant impact of the conjugate heat transfer is observed and requires fluid-solid thermal coupling to describe accurately the wall temperature and the flame behavior. These findings may have important implications for flame stabilization and thermal fatigue in practical systems such as liquid rocket engine injectors. The demonstrated feasibility and relevance of thermally coupled fluid-solid simulations allows to remove the uncertainty about the wall thermal conditions and improve the prediction and design of optimum burner geometries.

\section{Supplementary material}

Supplementary material associated with this article can be found, in the online version, at 10.1016/j.combustflame.2016.01. 004.

\section{References}

[1] G. Bruneaux, T. Poinsot, J.H. Ferziger, Premixed flame-wall interaction in a turbulent channel flow: budget for the flame surface density evolution equation and modelling, J. Fluid Mech. 349 (1997) 191-219.

[2] T. Poinsot, D. Haworth, G. Bruneaux, Direct simulation and modelling of flame-wall interaction for premixed turbulent combustion, Combust. Flame 95 $(1 / 2)(1993) 118-133$.

[3] O.A. Ezekoye, R. Greif, D. Lee, Increased surface temperatureeffects on wall heat transfer during unsteady flame quenching, Symp. (Int.) Combust. 24 (1) (1992) 1465-1472.

[4] J.H. Lu, O. Ezekoye, R. Greif, F. Sawyer, Unsteady heat transfer during side wall quenching of a laminar flame, Symp. (Int.) Combust. 23 (1) (1990) 441-446.

[5] B. Boust, J. Sotton, S. Labuda, M. Bellenoue, A thermal formulation for single-wall quenching of transient laminar flames, Combust. Flame 149 (3) (2007) 286-294.

[6] C.K. Westbrook, A.A. Adamczyk, G.A. Lavoie, A numerical study of laminar flame wall quenching., Combust. Flame 40 (1981) 81-99.

[7] F. Dabireau, B. Cuenot, O. Vermorel, T. Poinsot, Interaction of $\mathrm{H}_{2} / \mathrm{O}_{2}$ flames with inert walls, Combust. Flame 135 (1-2) (2003) 123-133.

[8] A. Delataillade, F. Dabireau, B. Cuenot, T. Poinsot, Flame/wall interaction and maximum heat wall fluxes in diffusion burners, Proc. Combust. Inst. 29 (2002) $775-780$.

[9] P. Popp, M. Baum, An analysis of wall heat fluxes, reaction mechanisms and unburnt hydrocarbons during the head-on quenching of a laminar methane flame, Combust. Flame 108 (3) (1997) 327-348.

[10] R. Owston, V. Magi, J. Abraham, Interactions of hydrogens flames with walls: influence of wall temperature, pressure, equivalence ratio and diluents, Int. J. Hydrogen Energy 32 (2007) 2094-2104.

[11] T.K. Kim, D.H. Lee, S. Kwon, Effects of thermal and chemical surface-flame interaction on flame quenching, Combust. Flame 146 (2006) 19-28.

[12] A. Gruber, R. Sankaran, E.R. Hawkes, J. Chen, Turbulent flame-wall interaction: a direct numerical simulation study, J. Fluid Mech. 658 (2010) 5-32.
[13] F. Duchaine, A. Corpron, L. Pons, V. Moureau, F. Nicoud, T. Poinsot, Development and assessment of a coupled strategy for conjugate heat transfer with large eddy simulation: application to a cooled turbine blade, Int. J. Heat Fluid Flow 30 (6) (2009) 1129-1141.

[14] L. Quartapelle, V. et Selmin, High-order Taylor-Galerkin methods for nonlinear multidimensional problems, Finite Elements in Fluids 76 (90) (1993) 46.

[15] O. Colin, M. Rudgyard, Development of high-order Taylor-Galerkin schemes for LES, J. Comput. Phys. 162 (2) (2000) 338-371.

[16] S. Buis, A. Piacentini, D. Déclat, PALM: a computational framework for assembling high performance computing applications, Concurr. Comput. 18 (2) (2005) 231-245.

[17] F. Duchaine, S. Mendez, F. Nicoud, A. Corpron, V. Moureau, T. Poinsot, Conjugate heat transfer with large eddy simulation application to gas turbine components, Comptes Rendus Acad. Sci. Mécanique 337 (6-7) (2009) 550-561.

[18] T. Poinsot, T. Echekki, M.G. Mungal, A study of the laminar flame tip and implications for premixed turbulent combustion, Combust. Sci. Technol. 81 (1-3) (1992) 45-73.

[19] P. Boivin, C. Jiménez, A. Sanchez, F. Williams, An explicit reduced mechanism for $\mathrm{H}_{2}$-air combustion, Proc. Combust. Inst. 33 (1) (2011) 517-523.

[20] P. Saxena, F. Williams, Testing a small detailed chemical-kinetic mechanism for the combustion of hydrogen and carbon monoxide., Combust. Flame 145 (2006) 316-323.

[21] A. Sanchez, F.A. Williams, Recent advances in understanding of flammability characteristics of hydrogen, Prog. Energy Combust. Sci. 41 (2013) 1-55.

[22] D.G. Goodwin, CANTERA: An open-source, object-oriented software suite for combustion, NSF Workshop on Cyber-based Combustion Science, National Science Foundation, NSF Headquarters, Arlington, VA (2006).

[23] D.Y. Peng, D.B. Robinson, A new two-constant equation of state, Ind. Eng. Chem. Fundam. 15 (1) (1976) 59-64.

[24] B.E. Poling, J.M. Prausnitz, J.P. O'Connell, The properties of gases and liquids, 5th ed., McGraw-Hill, 2001

[25] T.-H. Chung, L.L. Lee, K.E. Starling, Application of kinetic gas theories and multiparameter correlation for prediction of dilute gas viscosity and thermal conductivity, Ind. Eng. Chem. Fundam. 23 (1984) 8-13.

[26] V. Giovangigli, L. Matuszewski, F. Dupoirieux, Detailed modeling of planar transcritical $\mathrm{H}_{2}-\mathrm{O}_{2}-\mathrm{N}_{2}$ flames, Combust. Theory Model. 15 (2) (2011) 141-182.

[27] A. Ruiz, L. Selle, Simulation of a turbulent supercritical hydrogen/oxygen flow behind a splitter plate: cold flow and flame stabilization, Seventh Mediterranean Combustion Symposium (2011).

[28] T. Schmitt, L. Selle, A. Ruiz, B. Cuenot, Large-eddy simulation of supercriticalpressure round jets, AIAA J. 48 (9) (2010) 2133-2144.

[29] J. Warnatz, Concentration-, pressure-, and temperature-dependence of the flame velocity in hydrogen-oxygen-nitrogen mixtures, Combust. Sci. Technol. 26 (1981) 203-213.

[30] E. Lemmon, M. Huber, M. McLinden, NIST standard reference database 23: reference fluid thermodynamic and transport properties-REFPROP, Version 8.0, Technical Report, National Institute of Standards and Technology, Standard Reference Data Program, Gaithersburg, MD, 2007.

[31] M. Kuznetsov, R. Redlinger, W. Breitung, J. Grune, A. Friedrich, N. Ichikawa, Laminar burning velocities of hydrogen-oxygen-steam mixtures at elevated temperatures and pressures, Proc. Combust. Inst. 33 (2011) 895-903.

[32] W.M. Huang, S.R. Vosen, R. Greif, Heat transfer during laminar flame quenching, effect of fuels, Symp. (Int.) Combust. 21 (1) (1986) 1853-1860.

[33] S.R. Vosen, R. Greif, C.K. Westbrook, Unsteady heat transfer during laminar flame quenching., Symp. (Int.) Combust. 20 (1) (1984) 76-83.

[34] J. Sotton, B. Boust, S. Labuda, M. Bellenoue, Head-on quenching of transient laminar flame: heat flux and quenching distance measurements, Combust. Sci. Technol. 177 (7) (2005) 1305-1322. 